\title{
Konstanz prosodically annotated infant-directed speech corpus (KIDS Corpus)
}

\author{
Katharina Zahner, Muna Schönhuber, Janet Grijzenhout, Bettina Braun \\ Department of Linguistics, University of Konstanz \\ \{katharina.zahner|muna.schoenhuber|janet.grijzenhout|bettina.braun\}@uni-konstanz.de
}

\begin{abstract}
Knowing about infants' input is a prerequisite for some theories of first language acquisition. Here, we present the first prosodically annotated infant-directed speech corpus in German (KIDS Corpus) - a tool for formulating hypotheses and modeling acquisition processes in the prosodic domain and at the prosody-syntax interface. The multi-layered corpus consists of 524 intonation phrases (IPs) directed to infants younger than one year (196 IPs were extracted from the CHILDES database; 328 IPs were extracted from our own recordings). Pitch accents $(\mathrm{n}=832)$ and boundary tones $(n=1048)$ were labeled according to GToBI. Furthermore, we annotated the presence of unaccented syllables and pitch targets before and after the accentual syllables. We also tagged the word-prosodic structure of accented words and the syntactic category of all words. In the database, $41 \%$ of the words carry a pitch accent. Within the corpus, most words are verbs, but the words that bear a pitch accent are most often nouns. The majority of phrases start and end in low boundary tones. The most frequent pitch accent types are $\mathrm{H}^{*}$ and $\mathrm{L}+\mathrm{H}^{*}$. The data are discussed in terms of elicitation settings and potential implications of distribution frequencies on first language acquisition mechanisms.
\end{abstract}

Index Terms: corpus, infant-directed speech, prosody, pitch accent types, GToBI, German

\section{Introduction}

Within the last decade, a growing number of studies in the tradition of usage-based approaches to language acquisition (see [1]) have started to focus on the frequency of forms and constructions in children's input. The acquisition of these forms and constructions is found to be influenced by the frequency of occurrence with which children encounter them, with highly frequent patterns helping or facilitating acquisition processes (see [2] for a detailed discussion on input frequencies and first language acquisition).

More precisely, many studies have investigated the relationship between the syntactic complexity of adults' speech to children (child-directed speech, CDS) and children's language development, showing that a high input frequency of certain words or constructions increases the speed or ease with which children acquire them. [3, 4], for example, show that the input frequency of verbs is indicative of their acquisition rate. Furthermore, [5] demonstrate that the distributional patterns of complement-clause constructions predict children's acquisition trajectories. Evidence on frequency distributions and the role they play in CDS and children's language learning also comes from perception studies. For instance, [6] show that young children are able to make use of frequent co- occurrences of syntactic relations for the syntactic categorization of novel words.

Much less is known on the relationship between frequency distributions in infant-directed speech (IDS, which we define as speech to pre-linguistic infants) and very early acquisition processes. Studies on IDS have primarily focused on its phonetic properties and its communicative function, showing that IDS exhibits a slower speech rate, a higher mean pitch and larger pitch ranges [7, 8]. Functionally, IDS has been discussed in terms of social bonding $[9,10]$ and its potential in facilitating speech segmentation [11]. We argue that frequency distributions in the early input may be an interesting candidate for explaining findings in speech segmentation research. Specifically, [12] show that nouns are segmented earlier from fluent speech than verbs. The authors argue that nouns are prosodically more salient than verbs due to the accentuation pattern of the sentence [12]. Furthermore, [13] demonstrate that German nine-month-olds only treat stressed syllables as word onsets when they are high-pitched. Investigating the frequency distribution of accentual patterns in IDS might help to understand these findings better.

Here, we present a multi-layered prosodically annotated corpus for German IDS. Being the first of its kind, the KIDS Corpus allows for formulating and testing frequency-based hypotheses for language acquisition, specifically regarding the interplay between different linguistic areas (word-prosodic structure, morpho-syntax, intonation).

\section{KIDS Corpus}

\subsection{Materials}

The KIDS Corpus is composed of two main parts of data: a subset of German IDS utterances extracted from the CHILDES database [14] (196 IPs, 675 words, 3min 28sec of speech), as reported on in [15], and our own recordings in the Baby Speech Lab (BSL) at the University of Konstanz and in a home environment (328 IPs, 1339 words, $6 \mathrm{~min} 44 \mathrm{sec}$ of speech). In total, the KIDS Corpus includes IDS utterances from 16 different mothers (in total 524 IPs, 2014 words, $10 \mathrm{~min} 12 \mathrm{sec}$ of speech).

From the CHILDES database, we selected the speech of eight mothers who interacted with their infants (seven boys and one girl). For the BSL subset of the corpus, we recorded seven mothers together with their infants. All infants (five boys and two girls, age range: $0 ; 8.27$ to $0 ; 9.26$ ) came from monolingual German-speaking homes. The mothers were on average 33.3 years old ( $S D=3.8$ years), ranging from 30 to 40 years. Six of the mothers grew up in the southern part of Germany (four in Baden-Wuerttemberg and two in Bavaria) and one mother came from Hesse (central part of Germany). The mother-infant-dyads were recorded in typical play 
situations for approximately two minutes in the lab using an Olympus LS-5 digital recorder at a sampling rate of $44.1 \mathrm{kHz}$ (24 bit). Mothers were given a picture book and some other toys, which they could use according to their infant's interest. They were instructed to play with their infant as they would do at home. The experimenter left the room during the recording sessions in order to increase the intimacy between mother and infant and to make the situation more natural. Additionally, we added 21 IPs from another mother-infant-dyad of a private video to this dataset. This infant was five months of age and both parents were native speakers of German.

\subsection{Annotation}

\subsubsection{Lexical information and word class}

All data were labeled using PRAAT [16] in ten tiers (see Figure 1). The utterances were first annotated orthographically on the lexical level, providing the intended representation (tier 1) and the actual realization (tier 2). For instance, the utterance "Schau mal, die küssen sich!" 'Look, they are kissing' is realized as [Jav ma:l dis krsn sıç], while the intended representation of this utterance would be / Jau ma:l di: krsən sıç/. This distinction captures elisions and simplifications, as well as dialectal deviations from the Standard German norm (which were rare overall). The word class of all words in the corpus was tagged on tiers 3 and 4 . Tier 3 presents broad labels for the syntactic categories, e.g., "verb" or "noun". On tier 4, we used labels from the Stuttgart-Tübingen-TagSet (STTS) [17], e.g., "VVIMP" for a full verb in the imperative mode, "VAINF" for an auxiliary verb in the infinitive.

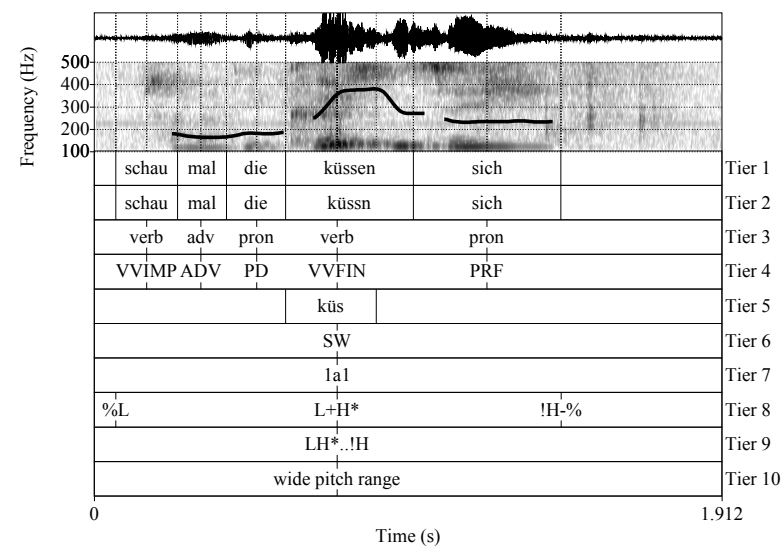

Figure 1: Example utterance from KIDS; the figure shows a smoothed f0-contour and all ten annotation layers.

\subsubsection{Prosody}

We first annotated the accented syllables orthographically (tier 5). We performed four different prosodic analyses. First, the word-prosodic structure of each accented word was tagged using "S" for strong syllables and "W" for weak ones (tier 6). Secondary stress was marked by "s", e.g., "Sandeleimer" "toy bucket' ['zandəl,ZaIme] received the label "SWsW".

The presence (or absence) of unaccented syllables before and after the accentual syllable was annotated on tier 7 . There were four cases: $0 \mathrm{a} 0$ (no unaccented syllable(s) on either side of the accented syllable "a", i.e., an IP boundary or accented syllable preceding and following "a"), 1a1 (unaccented syllable(s) on both sides of the accented syllable), 0a1 (unaccented syllable(s) only to the right of the accented syllable), 1a0 (unaccented syllable(s) only to the left of the accented syllable). Note that this classification was performed irrespective of word boundaries. Table 1 shows some example utterances for each category.

Table 1. Example utterances from KIDS showing the four cases of the availability of unaccented syllables on both sides of the accentual syllable and possible word-prosodic structures for each case.

\begin{tabular}{|l|c|l|l|}
\hline 0a0 & \multicolumn{1}{|c|}{ 1a1 } & \multicolumn{1}{|c|}{ 0a1 } & \multicolumn{1}{c|}{ a0 } \\
\hline$\frac{\mathrm{Ja} !}{(\mathrm{S})}$ & $\frac{\text { Was willst du }}{(\mathrm{S})}$ & $\frac{\text { Schau mal }}{(\mathrm{S})}$ & Mit $\frac{\text { Sand }}{(\mathrm{S})}$ \\
\hline- & $\begin{array}{c}\text { die Menschen } \\
(\mathrm{SW})\end{array}$ & $\frac{\text { Katze }}{(\mathrm{SW})}$ & - \\
\hline- & $\begin{array}{l}\text { Papier bleibt da } \\
(\mathrm{WS})\end{array}$ & - & $\begin{array}{l}\text { kaputt } \\
(\mathrm{WS})\end{array}$ \\
\hline
\end{tabular}

The intonational annotation was provided by two trained annotators (first and last author). Pitch accents and boundary tones were labeled according to GToBI (German Tone and Break Indices) [18] (tier 8), a widely used annotation system in the framework of autosegmental phonology (see [19] for an overview). The pitch accent/boundary tone inventory and our labeling conventions are described in more detail in [15].

Finally, if unaccented syllables were present on both sides of the accented syllable (1a1-condition), we annotated the two intonational targets before and after the accented syllable, resulting in a sequence of three pitch events (tier 9). The main motivation for this analysis was that we do not (yet) know whether the movement leading to the accented syllable (the so called "onglide" [20]) or the movement away from the accented syllable (the so called "offglide") or both are perceptually relevant for German infants. (Note that there is an ongoing debate regarding German adult perception on this issue, see, for example, $[21,22])$. We do not propose to introduce tritonal pitch accent types for the intonational description of German IDS. We merely provide a more detailed analysis of the pitch movements in the vicinity of the accentual syllable that is not based on a specific phonological theory. An example label for this three-tone-sequence analysis is $L^{*} \mathrm{H}$, i.e., an $\mathrm{L}^{*}$ accent that is preceded by an unaccented low-pitched syllable and followed by an unaccented highpitched syllable. If the preceding or following pitch target was not associated with the immediately adjacent syllable, this separation of pitch targets was indicated by “..” (e.g., LH*..L, see [15]). The last tier (tier 10) provides space for comments and remarks.

\section{Results and Discussion}

The multi-layered nature of the corpus allows us to analyze various relations of different prosodic aspects. Here, we concentrate on the distribution of syntactic categories and the word-prosodic structure, the distributional frequencies of boundary tones, pitch accent types, and three-tone-sequences.

\subsubsection{Accentuation of different word classes}

The most frequent word class are verbs (23\%), followed in frequency by pronouns $(19 \%)$, adverbs $(18 \%)$ and nouns $(12 \%)$, see Figure 2. 
Within the 524 IPs, 832 words are accented. Thus, an IP contains 1.6 pitch accents on average. $41 \%$ of the words carry a pitch accent (832 out of 2014). In total, $26 \%$ of the accented words are nouns, $25 \%$ are verbs, $16 \%$ are adverbs, and $10 \%$ are adjectives, see Figure 2. Not surprisingly, most of the accented words follow a typical Germanic word-prosodic structure [23-25]: 52\% are monosyllabic (S), followed in frequency by trochaic words (SW, 30\%). Other structures are considerably less frequent (e.g., WS: 4\%, SWW: 4\%)

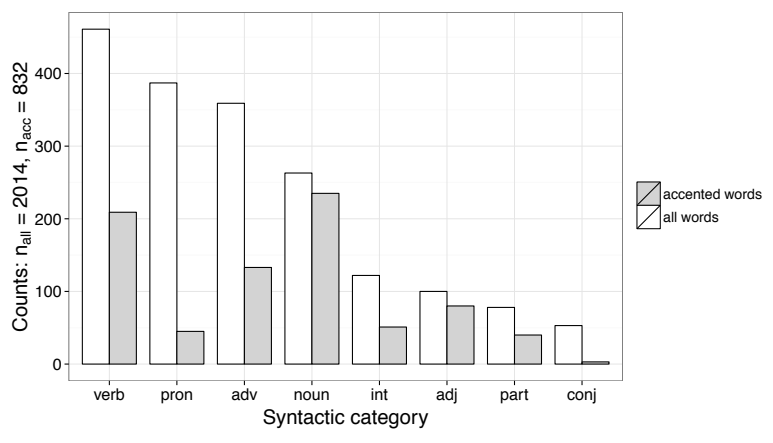

Figure 2: Distribution of most frequent syntactic categories within KIDS, across accented words (grey) and all words (white).

\subsubsection{GToBI}

Boundary tones. The corpus comprises 524 initial and 524 final boundary tones. In the majority of cases, the utterances start with a low boundary tone (69\% of the IPs). The annotators further identified some cases in which the boundary is neither strictly $\% \mathrm{~L}$ nor $\% \mathrm{H}$; these 10 cases $(2 \%)$ were only found before accents starting with a low tonal target $\left(\mathrm{L}^{*}+\mathrm{H}\right.$, $\mathrm{L}+\mathrm{H}^{*}$ or $\left.\mathrm{L}^{*}\right)$. For the current analysis, these intermediate cases are labeled as $\% \mathrm{M}$ (note that this label deviates from the original GToBI inventory for boundary tones, see [18]). Future research is necessary to determine whether this intermediate boundary tone level, which is indeed rare but obviously present, is a peculiarity of the current dataset or whether an intermediate category for IDS may be useful for the transcription of IDS.

The most frequent final boundary tone is L- $\%(46 \%$ of the IPs). The next frequent patterns are a high plateau (H-\%, 25\%) and a low rising boundary tone (L-H\%, 13\%). Incomplete falls $(! \mathrm{H}-\%, 7 \%)$ and high rises $\left(\mathrm{H}-{ }^{\wedge} \mathrm{H} \%, 7 \%\right)$ are least frequent. When grouping the boundary tones according to their perceptual impression, low/falling boundary tones (L-\%) constitute the most frequent pattern $(46 \%)$, followed in frequency by plateau-patterns $(\mathrm{H}-\%, \mathrm{l}-\mathrm{H}-\% ; 32 \%)$ and rising utterance endings ( $\left.\mathrm{L}-\mathrm{H} \%, \mathrm{H}-{ }^{\wedge} \mathrm{H} \% ; 20 \%\right)$. As discussed by $[26$, 27] on German ADS, the two plateau-patterns (H-\%, !H-\%) are usually accompanied by considerable segmental lengthening.

Pitch accent types. Overall, the most frequent accent types are $\mathrm{H}^{*}$ and $\mathrm{L}+\mathrm{H}^{*}$, each occurring in more than $25 \%$ of the accents. The low-pitched monotonal accent $\left(\mathrm{L}^{*}\right)$ is also common $(18 \%)$. It is conceivable that $\mathrm{H}^{*}$ and $\mathrm{L}+\mathrm{H}^{*}$ accents are frequent since these pitch accent types constitute the default accents for new and contrastive referents in German [28]. $\mathrm{L}^{*}$ accents are often followed by a high tone, in particular a high boundary tone (see analysis of three-tonesequences in Table 4). To generalize differences across datasets, we calculated a binomial logistic regression model with dataset as fixed factor and mother as random factor. The results showed that in the CHILDES subset $\mathrm{L}^{*}$ accents are significantly more frequent than in the utterances recorded in our lab $(25 \%$ vs. $13 \%$; $=0.003)$. Accents with a high leading tone $\left(\mathrm{H}+\mathrm{L}^{*}, \mathrm{H}+\mathrm{H}^{*}\right)$, which are appropriate to signal accessible referents in German, e.g., [29], are only sparsely represented in the corpus ( $6 \%$ and $2 \%$, respectively). This shows that IDS, a speech style that is characterized by many repetitions [30], does not automatically trigger the use of a pragmatically expected pitch accent type. This is in line with [31], who show that when talking to children, adults did not de-accent given referents as consistently as when talking to adults, instead they used more high-pitched accent types for given referents.

Across word classes, we observed the following pitch accent type distributions: While nouns are most often realized with an $\mathrm{L}+\mathrm{H}^{*}$ accent $(38 \%)$, followed in frequency by $\mathrm{H}^{*}$ $(24 \%)$ and $L^{*}(17 \%)$, accented verbs receive most often an $\mathrm{H}^{*}$ $(34 \%)$, followed in frequency by $\mathrm{L}^{*}(20 \%)$ and $\mathrm{L}+\mathrm{H}^{*}(17 \%)$. Accented adverbs, the third most frequent syntactic category across accented words, are most often realized with an $\mathrm{H}^{*}$ (33\%), followed by $\mathrm{L}+\mathrm{H}^{*}(26 \%)$ and $\mathrm{L}^{*}(17 \%)$.

Table 2. Distribution of GToBI boundary tones (final and initial), split by dataset.

\begin{tabular}{|c|c|c|c|}
\hline Label & $\begin{array}{c}\text { KIDS } \\
\text { (524 IPs) }\end{array}$ & $\begin{array}{c}\text { CHILDES } \\
\text { (196 IPs) }\end{array}$ & $\begin{array}{c}\text { BSL } \\
\text { (328 IPs) }\end{array}$ \\
\hline$\% \mathrm{~L}$ & $69 \%$ & $62 \%$ & $73 \%$ \\
$\% \mathrm{H}$ & $29 \%$ & $35 \%$ & $25 \%$ \\
$\% \mathrm{M}$ & $2 \%$ & $3 \%$ & $2 \%$ \\
\hline $\mathrm{L}-\%$ & $46 \%$ & $40 \%$ & $50 \%$ \\
\hline $\mathrm{H}-\%$ & $25 \%$ & $28 \%$ & $24 \%$ \\
$! \mathrm{H}-\%$ & $7 \%$ & $11 \%$ & $5 \%$ \\
\hline $\mathrm{L}-\mathrm{H} \%$ & $13 \%$ & $10 \%$ & $15 \%$ \\
$\mathrm{H}-{ }^{\wedge} \mathrm{H} \%$ & $7 \%$ & $10 \%$ & $5 \%$ \\
\hline
\end{tabular}

Table 3. Distribution of GToBI pitch accent types, split by dataset.

\begin{tabular}{|c|c|c|c|}
\hline Label & $\begin{array}{c}\text { KIDS } \\
(\mathbf{n}=\mathbf{8 3 2})\end{array}$ & $\begin{array}{c}\text { CHILDES } \\
(\mathbf{n}=\mathbf{3 1 1})\end{array}$ & $\begin{array}{c}\text { BSL } \\
(\mathbf{n}=\mathbf{5 2 1})\end{array}$ \\
\hline $\mathrm{H}^{*}$ & $31 \%$ & $30 \%$ & $32 \%$ \\
\hline$! \mathrm{H}^{*}$ & $8 \%$ & $5 \%$ & $10 \%$ \\
\hline $\mathrm{L}+\mathrm{H}^{*}$ & $27 \%$ & $20 \%$ & $31 \%$ \\
\hline $\mathrm{L}^{*}$ & $18 \%$ & $25 \%$ & $13 \%$ \\
\hline $\mathrm{L}^{*}+\mathrm{H}$ & $8 \%$ & $11 \%$ & $6 \%$ \\
\hline $\mathrm{H}+\mathrm{L}^{*}$ & $6 \%$ & $7 \%$ & $5 \%$ \\
\hline $\mathrm{H}+! \mathrm{H}^{*}$ & $2 \%$ & $3 \%$ & $1 \%$ \\
\hline
\end{tabular}

\subsubsection{Three-tone-sequences}

In this subsection, we present the results for the three-tonesequences in accents that were surrounded by at least one unaccented syllable on both sides (1a1). For the sake of clarity, the results are simplified in two respects: First, Table 4 ignores scaling differences, i.e., an $\mathrm{L}+\mathrm{H}^{*} ! \mathrm{H}-\%$ (see Figure 1) is counted as LH*L. Second, it is not taken into account whether a preceding or following pitch target is associated with a syllable adjacent to the accented syllable or is realized later, i.e., an $\mathrm{LH}^{*} . . \mathrm{L}$ notation is counted as $\mathrm{LH}^{*} \mathrm{~L}$ here. 
In total, the relevant 1a1-cases account for more than half of the data (426 accented syllables). By far the most frequent accentual pattern is a rising-falling movement $\left(\mathrm{LH}^{*} \mathrm{~L}\right)$, which occurs in $34 \%$ of the cases. Most of the accented words following this accentual pattern are disyllabic (SW, 40\%) or monosyllabic (S, 34\%); $45 \%$ are nouns and $27 \%$ are verbs. The second most common accentual pattern is LL*H. i.e., a low accentual tone preceded by a low and followed by a high tone, occurring in $14 \%$ of the cases (again disyllabic words are most common ( $\mathrm{SW}, 48 \%$ ), followed by monosyllabic words (S, 29\%); nouns and verbs are almost equally frequent $(33 \%$ and $31 \%$, respectively)). Note that the overall pattern (i.e., high-toned pitch accents more frequent than low-toned accents) is similar to the frequency distribution for German ADS, see e.g., [32]. The high frequency of $\mathrm{LH}^{*} \mathrm{~L}$ in the input might be attributed to its use for introducing new referents into the discourse [28], a function many mothers made use of when interacting with their infants. The second most common pattern, LL*H, might be traced back to the use of this particular pattern in many polar questions [18], which frequently occur in infants' input [33,34], and to a regional influence $[35,36]$. For the sequence $L^{*} \mathrm{H}$, we again observed a distribution difference across subsets: $L L^{*} \mathrm{H}$ patterns are significantly more frequent in the CHILDES subset than in the BSL recordings ( $20 \%$ vs. $11 \%, \mathrm{p}=0.04)$.

Table 4. Distribution of f0-movement around the accentual syllable (*) in lal-cases.

\begin{tabular}{|c|c|c|c|}
\hline $\begin{array}{c}\text { F0-movement } \\
\text { around } \\
\text { accentual tone }\end{array}$ & $\begin{array}{c}\text { KIDS } \\
(\mathbf{n}=\mathbf{4 2 6})\end{array}$ & $\begin{array}{c}\text { CHILDES } \\
(\mathbf{n}=\mathbf{1 3 0})\end{array}$ & $\begin{array}{c}\text { BSL } \\
(\mathbf{n}=\mathbf{2 9 6})\end{array}$ \\
\hline $\mathrm{LH}{ }^{*} \mathrm{~L}$ & $34 \%$ & $28 \%$ & $36 \%$ \\
\hline $\mathrm{HH}{ }^{*} \mathrm{~L}$ & $8 \%$ & $4 \%$ & $10 \%$ \\
\hline $\mathrm{LH}{ }^{*} \mathrm{H}$ & $12 \%$ & $13 \%$ & $11 \%$ \\
\hline & & & \\
\hline $\mathrm{HL} * \mathrm{~L}$ & $12 \%$ & $15 \%$ & $11 \%$ \\
\hline $\mathrm{HL} * \mathrm{H}$ & $7 \%$ & $7 \%$ & $7 \%$ \\
\hline $\mathrm{LL}{ }^{*} \mathrm{H}$ & $14 \%$ & $20 \%$ & $11 \%$ \\
\hline & & & \\
\hline $\mathrm{TT} * \mathrm{~T}$ & $6 \%$ & $4 \%$ & $6 \%$ \\
\hline $\mathrm{LM}^{*} \mathrm{H}$ & $1 \%$ & $4 \%$ & $<1 \%$ \\
\hline $\mathrm{HM}^{*} \mathrm{~L}$ & $7 \%$ & $5 \%$ & $7 \%$ \\
\hline
\end{tabular}

\section{General Discussion}

We present KIDS, the first prosodically annotated corpus of German IDS. The corpus consists of two different subsets: recordings retrieved from CHILDES and our own recordings in our Baby Speech Lab. Data were annotated on different layers in order to allow for analyses of the interplay between different prosodic areas and at the prosody-syntax interface.

Regarding segmentation processes, our results help to explain the finding that nouns are extracted earlier from fluent speech than verbs [12]. The majority of words uttered by mothers in KIDS are verbs (nearly one quarter of all words). However, of the accented words, nouns represent the most frequent word class $(26 \%$ of the cases). Accented words are perceptually more prominent than unaccented words, which in turn makes nouns easier to be detected. Furthermore, nouns are not only more often accented than verbs, but they are also realized with accent types that have been shown to make words most prominent in the utterance $\left(\mathrm{L}+\mathrm{H}^{*}\right.$ and $\mathrm{H}^{*}$, see [37] on adult prominence judgments of different pitch accent types in German). In our data, accented nouns more often receive an $\mathrm{L}+\mathrm{H}^{*}$ or $\mathrm{H}^{*}$ accent than verbs. It is thus conceivable that nouns provide a gateway to language acquisition, independent of other properties that make early nouns special (e.g., concreteness, referentiality). Moreover, the results presented above provide an explanation of another finding from a recent segmentation study [13], which showed that only high-pitched stressed syllables (but not low-pitched ones) are taken as word onsets by German infants. The high frequency of $\mathrm{LH}^{*} \mathrm{~L}$ in the corpus, compared to other patterns used in [13] $\left(\mathrm{LL}^{*} \mathrm{H}\right.$, HL*L), might account for this finding.

We find slightly different accent type distributions for the two subsets, in particular regarding the rising contour LL*H. A dialectal explanation is not very likely since the mothers' dialectal background is comparable in the two subsets of the corpus. We instead interpret this distributional difference as a consequence of the elicitation setting. Mothers in the BSL subset were aware of the fact that it was their speech we were interested in. Our participants often engaged in picture book activities, talkatively showing their infants the objects displayed. Even though the recording settings in the CHILDES subset also involved play situations [38], it is not clear how aware the mothers were of the fact that their speech was recorded/analyzed as well. Our assumption is that the mothers' primary intention in the CHILDES database might have been to make their infants talk. Encouraging an infant's turn is likely signaled by rising contours, as shown in [10, 39, 40], while situations in which mothers played the "dominant" role in the conversational setting might have resulted in more highpitched accentual syllables. Further research is needed regarding the functional aspect of IDS. Currently, we are analyzing the form-function mapping, i.e., the distribution of accentual patterns in different communicative situations.

\section{Conclusion}

To conclude, the KIDS Corpus provides a useful tool for testing and generating hypotheses about first language acquisition research. The TextGrids can be downloaded from http://ling.uni-konstanz.de/pages/home/braun/KIDS.html; the corresponding wav-files are available upon request. The files allow researchers to retrieve not only detailed prosodic or syntactic information about IDS but also information on the prosody-syntax interface, i.e., interdependent information on prosodic aspects and syntactic categories.

\section{Acknowledgements}

We thank Isabelle Auriga, Andrea Beeken, Sophie Egger, Angela James and Stephanie Gustedt for help with preparation and analyses of the data and Clara Huttenlauch for writing PRAAT scripts for TextGrid preparation and designing the KIDS homepage. We further appreciate discussion of data at the DIMA (Annotation Guidelines for German Intonation) meeting in Potsdam (March 2015). We owe special thanks to Brian MacWhinney and Yvan Rose from the CHILDES team for their support with data conversion in order to make the data available on the CHILDES online database soon. The project was partly funded by the Excellence Initiative of the University of Konstanz (LingVisAnn 663/13). 


\section{References}

[1] M. Tomasello, Constructing a language: A usage-based theory of language acquisition. Cambridge, Mass. [u.a.]: Harvard University Press, 2003.

[2] E. Lieven, "Input and first language acquisition: Evaluating the role of frequency," Lingua, vol. 120, pp. 2546-2556, 2010.

[3] A. L. Theakston, E. Lieven, J. M. Pine, and C. F. Rowland, "Going, going, gone: the acquisition of the verb 'go'," Journal of Child Language, vol. 29, pp. 783-811, 2002.

[4] L. R. Naigles and E. Hoff-Ginsberg, "Why are some verbs learned before other verbs? Effects of input frequency and structure on children's early verb use," Journal of Child Language, vol. 25, pp. 95-120, 1998.

[5] S. Brandt, E. Lieven, and M. Tomasello, "Development of word order in German complement-clause constructions: Effects of input frequencies, lexical items, and discourse function," Language, vol. 86, pp. 583-610, 2010.

[6] B. Höhle, J. Weissenborn, D. Kiefer, A. Schulz, and M. Schmitz, "Functional elements in infants' speech processing: The role of determiners in the syntactic categorization of lexical elements," Infancy, vol. 5, pp. 341-353, 2004.

[7] A. Fernald, T. Taeschner, J. Dunn, M. Papoušek, B. de BoyssonBardies, and I. Fukui, "A cross-language study of prosodic modifications in mothers' and fathers' speech to preverbal infants," Journal of Child Language, vol. 16, pp. 477-501, 1989.

[8] A. Fernald and T. Simon, "Expanded intonation contours in mothers' speech to newborns," Developmental Psychology, vol. 20, pp. 104-113, 1984.

[9] P. F. Dominey and C. Dodane, "Indeterminacy in language acquisition: The role of child directed speech and joint attention," Journal of Neurolinguistics, vol. 17, pp. 121-145, 2004.

[10] M. Papoušek, H. Papoušek, and D. Symmes, "The meanings of melodies in motherese in tone and stress languages," Infant Behavior and Development, vol. 14, pp. 415-440, 1991.

[11] E. D. Thiessen, E. A. Hill, and J. R. Saffran, "Infant-directed speech facilitates word segmentation," Infancy, vol. 7, pp. 53-71, 2005.

[12] T. Nazzi, L. C. Dilley, A. M. Jusczyk, S. Shattuck-Hufnagel, and P. W. Jusczyk, "English-learning infants' segmentation of verbs from fluent speech," Language and Speech, vol. 48, pp. 279-298, 2005 .

[13] K. Zahner, M. Schönhuber, and B. Braun, "The limits of metrical segmentation: Intonation modulates infants' extraction of embedded trochees," Journal of Child Language, avilable on CJO 2015.

[14] B. MacWhinney, The CHILDES project: Tools for analyzing talk., 3rd ed. vol. 2: The Database. Mahwah, NJ: Lawrence Erlbaum Associates, 2000.

[15] K. Zahner, M. Pohl, and B. Braun, "Pitch accent distribution in German infant-directed speech," in Proceedings of Interspeech, Dresden, 2015.

[16] P. Boersma and D. Weenink. (2014). Praat: Doing phonetics by computer. Version 5.3.84 [Computer program].

[17] A. Schiller, S. Teufel, C. Stöckert, and C. Thielen, "Guidelines für das Tagging deutscher Textcorpora mit STTS (Kleines und großes Tagset)," Universitäten Stuttgart und Tübingen [Universities of Stuttart und Tübingen] 1999.

[18] M. Grice, S. Baumann, and R. Benzmüller, "German intonation in autosegmental-metrical phonology," in Prosodic Typology. The Phonology of Intonation and Phrasing, J. Sun-Ah, Ed., Oxford: Oxford University Press, 2005, pp. 55-83.

[19] D. R. Ladd, Intonational phonology vol. 119. Cambridge [u.a.]: Cambridge University Press, 2008.

[20] D. Crystal, Prosodic systems and intonation in English vol. 1. Cambridge: University Press, 1969.

[21] F. Kügler and A. Gollrad, "Production and perception of contrast: The case of the rise-fall contour in German," Frontiers in Psychology, vol. 6, p. 1254, 2015.
[22] S. Ritter and M. Grice, "The role of tonal onglides in German nuclear pitch accents," Language and Speech, vol. Mar 58(Pt 1), pp. 114-128, 2015.

[23] A. Cutler and D. M. Carter, "The predominance of strong initial syllables in the English vocabulary," Computer Speech \& Language, vol. 2, pp. 133-142, 1987.

[24] V. J. van Heuven and P. J. Hagman, "Lexical statistics and spoken word recognition in Dutch," in Linguistics in the Netherlands, P. Coopmans and A. Hulk, Eds., Dordrecht: Foris, 1988.

[25] R. Wiese, The phonology of German: The phonology of the world's languages vol. Repr. Oxford [u.a.]: Oxford Univ. Press, 2006.

[26] J. Mayer, "Transcription of German intonation - the Stuttgart system," University of Stuttgart, Tech. Rep. 1995

[27] J. Peters, "Tonal effects on rhythm in west middle German," in Proceedings of the $1^{\text {st }}$ International Conference on Speech Prosody, Aix-en-Provence, 2002, pp. 567-570.

[28] K. Kohler, "Terminal intonation patterns in single-accent utterances of German: Phonetics, phonology and semantics," Arbeitsberichte des Instituts für Phonetik und digitale Sprachverarbeitung der Universität Kiel (AIPUK), vol. 25, pp. 115-185, 1991

[29] S. Baumann and M. Grice, "The intonation of accessibility," Journal of Pragmatics, vol. 38, pp. 1636-1657, 2006.

[30] L. J. Ferrier, "Some observations of error in context," in The development of communication, N. Waterson and C. E. Snow, Eds., New York: Wiley, 1978, pp. 301-309.

[31] T. Grünloh, M. Tomasello, and E. Lieven, "Young children's intonational marking of new, given and contrastive referents," Language Learning and Development, vol. 11, pp. 95-127, 2015.

[32] B. Peters, K. Kohler, and T. Wesener, "Melodische Satzakzentmuster in prosodischen Phrasen deutscher Spontansprache - Statistische Verteilung und sprachliche Funktion" [Melodic sentence accent patterns in spontaneous German prosodic phrases - A statistical distribution and linguistic function], in Prosodic Structures in German Spontaneous Speech (AIPUK 35a), K. Kohler, F. Kleber, and B. Peters, Eds., Kiel: IPDS, 2005, pp. 185-201.

[33] A. Fernald and C. Mazzie, "Prosody and focus in speech to infants and adults," Developmental Psychology, vol. 27, pp. 209$221,1991$.

[34] T. Cameron-Faulkner, E. Lieven, and M. Tomasello, "A construction based analysis of child directed speech," Cognitive Science, vol. 27, pp. 843-873, 2003.

[35] F. Kügler, The intonational phonology of Swabian and Upper Saxon. Tübingen: Niemeyer, 2007.

[36] M. Atterer and D. R. Ladd, "On the phonetics and phonology of "segmental anchoring" of F0: Evidence from German," Journal of Phonetics, vol. 32, pp. 177-197, 2004.

[37] S. Baumann and C. Röhr, "The perceptual prominence of pitch accent types in German," Proceedings of the $18^{\text {th }}$ International Congress of the Phonetic Sciences, Glasgow, 2015.

[38] H. Behrens, "The input-output relationship in first language acquisition," Language \& Cognitive Processes, vol. 21, pp. 2-24, 2006.

[39] M. L. Ryan, "Contour in context," in Recent advances in the psychlogy of language, R. N. Campbell and P. T. Smith, Eds., New York: Plenum, 1978.

[40] I. Auriga, "Intonation in infant-directed-speech - Zur Funktion prosodischer Kategorien" [Intonation in infant-directed speech A functional analysis of prosodic categories], BA Thesis, Department of Linguistics, University of Konstanz, Konstanz, 2016. 